\title{
Effects of intermedin on proliferation, apoptosis and the expression of OPG/RANKL/M-CSF in the MC3T3-E1 osteoblast cell line
}

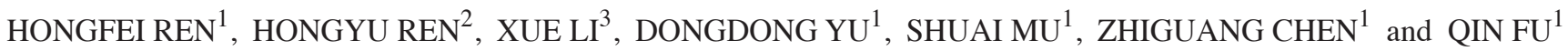 \\ ${ }^{1}$ Department of Orthopedic Surgery, Shengjing Hospital of China Medical University, Shenyang, Liaoning 110004; \\ ${ }^{2}$ Department of Orthopedic Surgery, Gaizhou Central Hospital, Yingkou, Liaoning 115200; ${ }^{3}$ Department of Orthopedic Surgery, \\ First Affiliated Hospital of Liaoning Medical University, Jingzhou, Liaoning 121001, P.R. China
}

Received November 3, 2014; Accepted July 28, 2015

DOI: $10.3892 / \mathrm{mmr} .2015 .4328$

\begin{abstract}
Bone remodeling is a vital physiological process of healthy bone tissue in humans. It is characterized by the formation of bone by osteoblasts and its resorption by osteoclasts, and the bone resorbed by osteoclasts is replaced through the differentiation and activity of osteoblasts. Imbalances in this vital process lead to pathological conditions, including osteoporosis. Intermedin (IMD) as a newly discovered peptide in the calcitonin (CT) family of peptides, which shares similar functions with CT, calcitonin gene-related peptide and amylin in bone resorption. However, the mechanism underlying its effect remains to be elucidated. This was investigated in the present study using the osteoblastic MC3T3-E1 cell line, which was treated with different doses of IMD $(0,1,10$ and $100 \mathrm{nM})$. Cell proliferation, apoptosis and the expression of receptor activator of NF- $\kappa \mathrm{B}$ ligand (RANKL), osteoprotegerin (OPG) and macrophage colony-stimulating factor (M-CSF) were measured following treatment using multiple detection techniques, including an MTT assay, flow cytometry, reverse transcription-quantitative polymerase chain reaction and western blot analysis. The resulting data demonstrated that IMD significantly inhibited the apoptosis of MC3T3-E1 cells induced by serum-free culture and dexamethasone, however, no significant effects on MC3T3-E1 cell proliferation were observed. IMD had additional functions on the MC3T3-E1 cells, including inhibition of the expression of RANKL and $\mathrm{M}-\mathrm{CSF}$, and promotion of the expression of OPG. Previous studies have also demonstrated that RANKL and M-CSF are two vital factor produced by osteoblasts to promote the maturation and differentiation of osteoclasts, and it has been
\end{abstract}

Correspondence to: Dr Qin Fu, Department of Orthopedic Surgery, Shengjing Hospital of China Medical University, 36 San Hao Street, Shenyang, Liaoning 110004, P.R. China

E-mail: fuqsjhospital@163.com

Key words: intermedin, osteoblast, macrophage colony-stimulating factor, nuclear factor- $\kappa \mathrm{B}$ ligand/osteoprotegerin, bone resorption reported that IMD can inhibit the osteoclast formation stimulated by RANKL and M-CSF. Together with these findings, the present study concluded that IMD reduces bone resorption by inhibiting osteoblast apoptosis, decreasing the RANKL/OPG ratio and the expression of $\mathrm{M}-\mathrm{CSF}$, and inhibiting osteoclast maturation and differentiation.

\section{Introduction}

Intermedin (IMD), also known as adrenomedullin 2 (ADM2), is a newly discovered member of the calcitonin family peptides, which was independently identified by two groups in $2004(1,2)$. IMD is expressed in a variety of organ systems, including the gastrointestinal tract, lungs, cardiovascular system, hypothalamus, pituitary gland, adrenal gland and placenta (2-6). Similar to other CT family members, including calcitonin gene-related peptide (CGRP) and AMD, IMD exerts its actions through receptor complexes comprising calcitonin receptor-like receptor (CRLR) and one of three receptor activity modifying proteins, (RAMP1, RAMP2 and RAMP3) (1,7), and stimulate the formation of cyclic AMP.

A series of physiological and pharmacological functions of IMD have been reported. IMD protects the mammalian vasculature, myocardium and kidney from acute ischemia-reperfusion injury, chronic oxidative stress and pressure-loading $(5,8)$. IMD also inhibits apoptosis, attenuates maladaptive tissue remodelling and preserves cardiac and renal functions $(9,10)$. Previously, it was reported that bone appears to be a common target for all the peptides of the calcitonin family, although the specific bone effects of the peptides vary (11). The administration of calcitonin produces rapid lowering of serum calcium levels, predominantly through the inhibition of bone resorption by osteoclasts (12). In vitro investigations and a number of animal experimental models have demonstrated that amylin and CGRP are also effective in inhibiting osteoclast activity and bone resorption (12). Susanne et al identified that IMD exhibits significant inhibitory effects on mouse calvarial bone matrix degradation stimulated by PTH and osteoclastogenesis (13), and IMD receptors, RAMPd and CRLP are expressed in osteoblasts (14). However, whether IMD can 
affect osteoblasts and is involved in bone resorption remains to be elucidated.

In the present study, the effects of IMD on the proliferation and apoptosis of osteoblasts were investigated. Subsequently, whether IMD is involved in osteoblastic and osteoclastic activity was determined by assessing molecules, which are closely associated with the processes, including receptor activator of NF- $\mathrm{NB}$ ligand (RANKL), osteoprotegerin (OPG) and macrophage colony-stimulating factor (M-CSF). The MC3T3-E1 osteoblast cell line was used as a cell model in vitro. In addition, the present study investigated the possible mechanism underlying the inhibitory effects of IMD on bone resorption.

\section{Materials and methods}

Reagents. Intermedin/Adrenomedullin-2 (IMD) was purchased from Phoenix Biotech Company. MTT was obtained from Sigma-Aldrich (St. Louis, MO, USA) and Annexin V-Fluorescein isothiocyanate (FITC)/propidium iodide (PI) kit from BD Biosciences (San Jose, CA, USA). The caspase-3 activity assay kit was purchased from Promega Corporation (Madison, WI, USA). Alkaline phosphatase (ALP) detection buffer was purchase from Sigma-Aldrich and the Micro BCA protein assay kit was obtained from Thermo Fisher Scientific (Waltham, MA, USA). All RNA primers and the PrimeScript RT-PCR kit were obtained from Takara, Bio, Inc. (Otsu, Japan). TRIzol reagent was obtained from Gibco Life Technologies (Carlsbad, CA, USA). Anti-OPG, RANKL, M-CSF and caspase-3 antibodies were purchased from Santa Cruz Biotechnology, Inc. (Dallas, TX, USA) The MC3T3-E1 mouse osteoblastic cell line was obtained from American Type Culture Collection (Manassas, VA, USA).

Mouse MC3T3-E1 cell culture. The MC3T3-E1 cells were cultured in minimum essential medium (MEM) containing 10\% fetal bovine serum (FBS; Gibco Life Technologies), $100 \mathrm{U} / \mathrm{ml}$ penicillin, $100 \mathrm{mg} / \mathrm{ml}$ streptomycin (Beyotime Institute of Biotechnology, Haimen, China) and $50 \mathrm{mg} / \mathrm{ml}$ of ascorbic acid (Sigma-Aldrich). The cells were maintained in a humidified, $95 \%$ air, $5 \% \mathrm{CO}_{2}$ atmosphere at $37^{\circ} \mathrm{C}$. The medium was replaced every 3 days, and the cells were subcultured using $0.05 \%$ trypsin with $0.01 \%$ EDTA (Beyotime Institute of Biotechnology).

Cell proliferation assay. The MC3T3-E1 cells, at a density of $3 \times 10^{3}$ cells/well, were seeded into 96 -well plates, cultured for $24 \mathrm{~h}$ at $37^{\circ} \mathrm{C}$ and then treated with different concentrations of IMD $(1,10$ or $100 \mathrm{nM})$ for $48 \mathrm{~h}$. Cell viability was detected by measuring the absorbance of each well at $490 \mathrm{~nm}$ using a Bio-Rad 680 microplate reader (Bio-Rad Laboratories, Inc., Hercules, CA, USA) and the experiment was performed five times. The proliferation rate was calculated from the optical density (OD) value and was used to determine the effect of IMD on MC3T3-E1 proliferation.

Osteoblast differentiation. The MC3T3-E1 cells $\left(3 \times 10^{5}\right)$ were cultured in MEM containing 10\% FBS, $50 \mathrm{mg} / \mathrm{ml}$ ascorbic acid and $10 \mathrm{mM} \beta$-glycerophosphate (Sigma-Aldrich) treated with $\operatorname{IMD}(1,10$ or $100 \mathrm{nM})$ at $37^{\circ} \mathrm{C}$. At differentiation days
7 and 14, the activity of ALP was measured. Briefly, the cells were washed twice with PBS and then lysed. The lysates were incubated in ALP detection buffer for $30 \mathrm{~min}$ at $37^{\circ} \mathrm{C}$ and were monitored at $405 \mathrm{~nm}$. Total protein was detected using a Micro BCA protein assay kit and read at $562 \mathrm{~nm}$. The relative activity of ALP was normalized to the total protein content of the sample $(405 / 562 \mathrm{~nm})$. In addition, the mRNA levels of osteoblast differentiation markers, OCN and BSP were measured, and Alizarin red staining (Sigma-Aldrich) was performed on differentiation days 14 and 21. For Alizarin red staining, the medium was removed, and the cell layer was rinsed with PBS and fixed in $70 \%$ ethanol for $1 \mathrm{~h}$ at $-20^{\circ} \mathrm{C}$. The cell layer was washed with deionized water and then the fixed cells were stained with $40 \mathrm{mM}$ Alizarin red S ( $\mathrm{pH} \mathrm{4.2)} \mathrm{for} 10 \mathrm{~min}$ at room temperature.

Cell apoptosis analysis. The apoptosis of the MCT3-E1 cells was quantified using flow cytometry. The cells $\left(3 \times 10^{5}\right)$ were cultured at $37^{\circ} \mathrm{C}$ in serum-free medium or $10^{-7} \mathrm{M}$ dexamethasone (DEX; Sigma-Aldrich) for $24 \mathrm{~h}$ in the absence or presence of 1-100 nM IMD. Treatment with 1\% FBS was used to determine the basal levels of apoptosis. Briefly, following treatment with IMD for $48 \mathrm{~h}$ at $37^{\circ} \mathrm{C}$, the cells were freshly harvested and washed with PBS. Subsequently $150 \mu \mathrm{l}$ chilled Annexin V binding buffer was added, followed by $5 \mu$ l Annexin V-FITC and incubation for $15 \mathrm{~min}$. During the final $5 \mathrm{~min}, 5 \mu \mathrm{l}$ PI was added and further incubated for $10 \mathrm{~min}$. Following staining, $350 \mu \mathrm{l}$ Annexin $\mathrm{V}$ binding buffer was added and the cells were analyzed using a BD FACSCalibur (BD Biosciences).

Caspase-3 activity was determined by measuring the cleavage of the Ac-DEVD-pNA chromogenic caspase substrate, which is a caspase-3 substrate. The OD value at $405 \mathrm{~nm}$ was determined to reflect the quantity of caspase-3. The specific caspase-3 activity, normalized to that of the total proteins of the cell, was then expressed as the fold change from the baseline caspase- 3 activity of the control cells.

Reverse transcription-quantitative polymerase chain reaction (RT-qPCR) analysis. The MC3T3-E1 cells were cultured for $48 \mathrm{~h}$ in the presence of 1-100 $\mathrm{nM}$ IMD. Following treatment, the mRNA of cells was extracted using TRizol reagent, and cDNA was synthesized using the PrimeScript RT-PCR kit. The quantity of samples used in the RT-qPCR were as follows: SYBR Green Mastermix $10 \mu \mathrm{l}$, cDNA $2 \mu \mathrm{l}$, forward primer $(10 \mu \mathrm{M}) 1 \mu \mathrm{l}$, reverse primer $(10 \mu \mathrm{M}) 1 \mu \mathrm{l}$ and $\mathrm{H}_{2} \mathrm{O} 5 \mu \mathrm{l}$. The sequences of the primers of RANKL, OPG, M-CSF, osteocalcin (OCN), bone sialoprotein (BSP) and the housekeeping $\beta$-actin gene are presented in Table I. qPCR was performed on a RotorGene real-time DNA amplification system using the following cycling protocol: $95^{\circ} \mathrm{C}$ denaturation for $10 \mathrm{~min}$, followed by 40 cycles of $95^{\circ} \mathrm{C}(10 \mathrm{sec}), 60^{\circ} \mathrm{C}$ annealing $(20 \mathrm{sec})$ and $72^{\circ} \mathrm{C}$ extension $(30 \mathrm{sec})$. The $2^{-\Delta \Delta \mathrm{CT}}$ method was used to determine the gene expression levels (15).

Western blot analysis. Following treatment with either serum-free medium or $10^{-7} \mathrm{MDEX}$ in the presence or absence of 1-100 nM IMD for $24 \mathrm{~h}$, the MC3T3-E1 cells were lysed in lysis buffer, containing $150 \mathrm{mM}$ TrisHCl (pH 7.4), $150 \mathrm{mM} \mathrm{NaCl}$, $0.1 \%$ SDS, $1 \%$ Triton X-100, $1 \%$ Nonidet P-40, protease inhibitor, $1 \mathrm{M} \mathrm{NaF}, 1 \mathrm{M}$ b-glycerophosphate, $0.5 \mathrm{M} \mathrm{Na}_{3} \mathrm{VO}_{4}, 1 \mathrm{M}$ 
Table I. Primer sequences used in reverse transcription-quantitative polymerase chain reaction analysis in the present study.

\begin{tabular}{|c|c|c|}
\hline Gene & Primer & Primer sequence $\left(5^{\prime}-3^{\prime}\right)$ \\
\hline OPG & $\begin{array}{l}\text { Forward } \\
\text { Reverse }\end{array}$ & $\begin{array}{l}\text { TGAGAGAACGAGAAAGACCTGC } \\
\text { CGGATTGAACCTGATTCCCTAT }\end{array}$ \\
\hline RANKL & $\begin{array}{l}\text { Forward } \\
\text { Reverse }\end{array}$ & $\begin{array}{l}\text { TCCTGAGACTCCATGAAAACGCAG } \\
\text { GCCACATCCAACCATGAGCCTTC }\end{array}$ \\
\hline M-CSF & $\begin{array}{l}\text { Forward } \\
\text { Reverse }\end{array}$ & $\begin{array}{l}\text { TTTTCCTGGGCATTGTGGTCT } \\
\text { AGGAGGTTCAGGGCTTCTTTG }\end{array}$ \\
\hline $\mathrm{OCN}$ & $\begin{array}{l}\text { Forward } \\
\text { Reverse }\end{array}$ & $\begin{array}{l}\text { GAGGGCAATAAGGTAGTGAA } \\
\text { CATAGATGCGTTTGTAGGC }\end{array}$ \\
\hline BSP & $\begin{array}{l}\text { Forward } \\
\text { Reverse }\end{array}$ & $\begin{array}{l}\text { CAGGGAGGCAGTGACTCTTC } \\
\text { AGTGTGGAAAGTGTGGCGTT }\end{array}$ \\
\hline$\beta$-actin & $\begin{array}{l}\text { Forward } \\
\text { Reverse }\end{array}$ & $\begin{array}{l}\text { CTGTGCCCATCTACGAGGGCTAT } \\
\text { TTTGATGTCACGCACGATTTCC }\end{array}$ \\
\hline
\end{tabular}

OPG, osteoprotegerin; RANKL, receptor activator of NF-кB ligand; M-CSF, macrophage colony-stimulating factor; OCN, osteocalcin; BSP, bone sialoprotein.

DTT, $1 \%$ sodium deoxycholate and 5 mM EDTA. Following 30 min incubation at $4^{\circ} \mathrm{C}$, the lysates were sonicated and centrifuged at $12,000 \mathrm{x}$ g for $10 \mathrm{~min}$ at $4^{\circ} \mathrm{C}$, and heated for $5 \mathrm{~min}$ at $95^{\circ} \mathrm{C}$. The samples were resolved on a SDS-PAGE gel and transferred onto a nitrocellulose membrane (EMD Millipore, Billerica, MA, USA). Immunoblotting was then performed using antibodies against rabbit polyclonal RANKL (cat. no. SC-9073), rabbit polyclonal OPG (cat. no. SC-11383), rabbit polyclonal M-CSF (cat. no. SC-13103), rabbit polyclonal caspase-3 (cat. no. SC-7148) and mouse monoclonal $\beta$-actin (cat. no. SC-8342). Following $1 \mathrm{~h}$ incubation at $25^{\circ} \mathrm{C}$ with 1:2,000 goat anti-rabbit secondary antibodies, the blots were visualized using enhanced chemiluminescence (7Sea Biotech, Shanghai, China) and quantified using a Gel-Pro-Analyzer 4.0 (Media Cybernetics, Inc., Rockville, MD, USA).

Statistical analysis. Data are presented as the mean \pm standard deviation, and all experiments were performed at least three times with similar results. Comparisons were made using a one-way analysis of variance and an unpaired t-test. Statistical analysis was performed using SPSS version 17.0 (SPSS, Inc., Chicago, IL, USA). $\mathrm{P}<0.05$ was considered to indicate a statistically significant difference.

\section{Results}

Effects of IMD on the proliferation and differentiation of MC3T3-E1 cells. Following treatment with different doses of IMD $(0,10$ or $100 \mathrm{nM})$ for $48 \mathrm{~h}$, the effects of IMD on the growth of MC3T3-E1 cells was determined using MTT assays (Fig. 1). The data revealed no significant enhancement in the proliferation of MC3T3-E1 cells exposed to IMD, compared with the control group $(\mathrm{P}>0.05)$. In addition, no significant effects on ALP activity, Alizarin red staining or the mRNA expression levels of OCN or BSP were observed $(\mathrm{P}>0.05$; Fig. 2). Therefore, IMD had no effect on the proliferation or

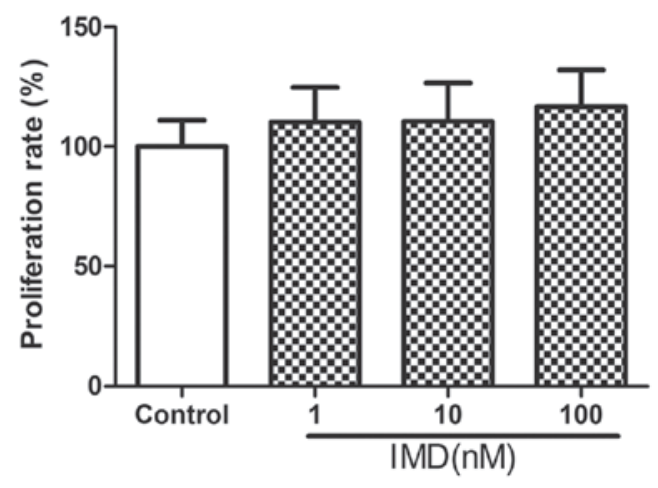

Figure 1. Effect of IMD on MC3T3-E1 cell proliferation was examined using an MTT assay. Cells were incubated with IMD (1-100 nM) for $48 \mathrm{~h}$. No significant differences were observed, compared with the control group. Data are presented as the mean \pm standard deviation. IMD, intermedin.

differentiation of MC3T3-E1 cells, and was unable to promote bone formation (data not shown).

Effects of IMD on the apoptosis of MC3T3-E1 cells. To examine the role of IMD on the apoptosis of MC3T3-E1 cells, the cells were cultured in serum-free medium or $10^{-7} \mathrm{M} \mathrm{DEX}$ with IMD (1-100 $\mathrm{nM}$ ) for $24 \mathrm{~h}$, and apoptotic progression was detected using flow cytometric analysis. FITC-conjugated annexin $\mathrm{V}$ was used to stain the early apoptotic biomarker, phosphoserine, at the cell surface, whereas PI was used to stain later apoptotic and necrotic cells. As shown in Fig. 3A, the number of PI-positive and annexin V-positive cells significantly decreased in the cells treated with $100 \mathrm{nM}$ IMD, compared with those in serum-free medium or $10^{-7} \mathrm{M}$ DEX alone $(\mathrm{P}<0.01)$.

As caspase-3 is important in the process of apoptosis, caspase- 3 activity and protein expression were measured to assess apoptosis in the present study. To evaluate the effect of IMD on caspase- 3 activity and protein expression, the 
A

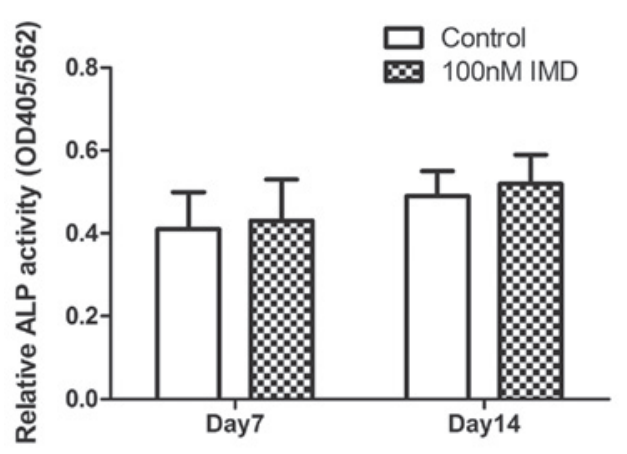

C
B

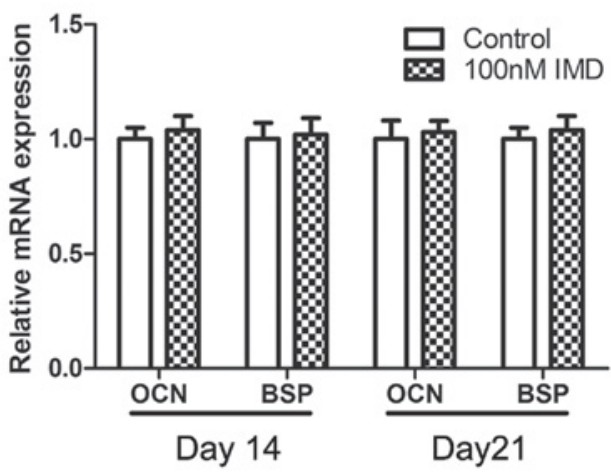

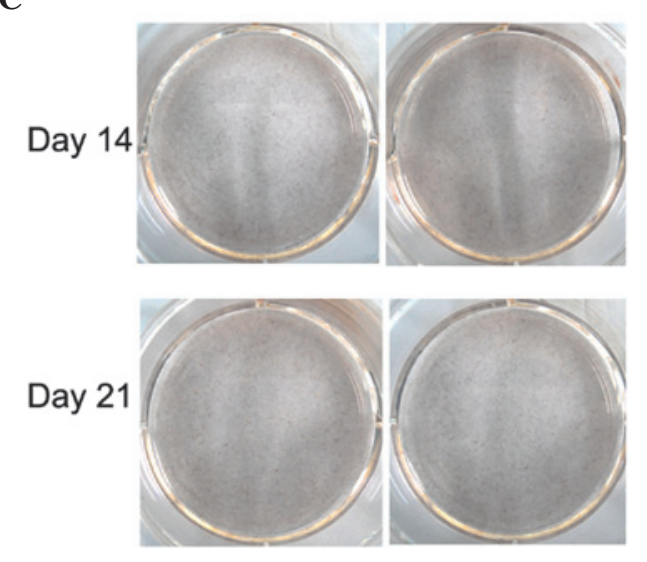

Figure 2. Effect of IMD on MC3T3-E1 cell differentiation. (A) Relative ALP activity. No differences were observed between the $100 \mathrm{nM}$ IMD group and the control group at days 7 or 14 following culture in osteoblastic differentiation medium. (B) Relative expression levels of osteogenic markers on days 14 and 21. No differences were observed in the mRNA levels of OCN and BSP. (C) Alizarin red staining of mineralized MC3T3-E1 cells on days 14 and 21 following osteogenic differentiation. No significant effect was observed. Data are presented as the mean \pm standard deviation. IMD, intermedin; ALP, alkaline phosphatase; OCN, osteocalcin; BSP, bone sialoprotein.

MC3T3-E1 cells cultured in serum-free medium or $10^{-7} \mathrm{MDEX}$ were treated with different doses of IMD between 1 and $100 \mathrm{nM}$ for $24 \mathrm{~h}$. The results indicated that IMD significantly decreased caspase- 3 activity and protein expression at a concentration of $100 \mathrm{nM}$, compared with the untreated cells at $24 \mathrm{~h}(\mathrm{P}<0.01$; Fig. 3B). These findings suggested that IMD inhibited the apoptosis of MC3T3-E1 cells (data not shown).

Effects of IMD on ratio of RANKL/OPG. The expression ratio of RANKL/OPG, which are synthesized by osteoblasts, represent bone resorption. To verify the expression of RANKL and OPG in the MC3T3-E1 cells treated with IMD, the present study performed RT-qPCR and western blot analysis. The results revealed that the expression of RANKL at the mRNA and protein levels were markedly downregulated by various doses of IMD, whereas the levels of OPG were significantly upregulated (Fig. 4). IMD at $100 \mathrm{nM}$ significantly decreased the mRNA and protein expression levels of RANKL $(\mathrm{P}<0.01)$, and upregulated the mRNA and protein expression levels of OPG $(\mathrm{P}<0.01)$. Therefore, IMD significantly improved the imbalance in the RANKL/OPG ratio $(\mathrm{P}<0.01)$, which is likely to induce an inhibitory effect on bone resorption.

Effects of IMD on the expression of M-CSF. M-CSF is another osteoblast-mediated activation marker of bone resorption.
As shown in Fig. 5, the expression levels of M-CSF were measured using RT-qPCR and western blot analysis. In the untreated group, the MC3T3-E1 cells expressed a basal level of M-CSF. By contrast, the level of M-CSF in the MC3T3-E1 cells was significantly altered following IMD treatment. The data demonstrated that IMD significantly downregulated the mRNA and protein expression levels of M-CSF $(\mathrm{P}<0.01)$, which suggested suppression of the osteoclast-mediated bone resorption by IMD.

\section{Discussion}

Osteoporosis is a common bone disease characterized by a reduction in bone mineral density and an increase in fracture risk, which affects quality of life (16). Bone is a dynamic tissue that constantly undergoes a process of renewal and repair (17) termed 'bone remodeling', in which a balance of bone formation by osteoblasts and resorption by osteoclasts continues throughout life $(18,19)$. This balance involves the coordinated regulation and interaction of two cell types, osteoclasts and osteoblasts $(17,20)$. Either a decrease in osteoblastic activity or an increase in osteoclastic activity in the bone can lead to imbalance by accelerating bone resorption (21).

Osteoblasts, which are derived from mesenchymal stem cells (MSCs), are responsible for the production of bone 
A
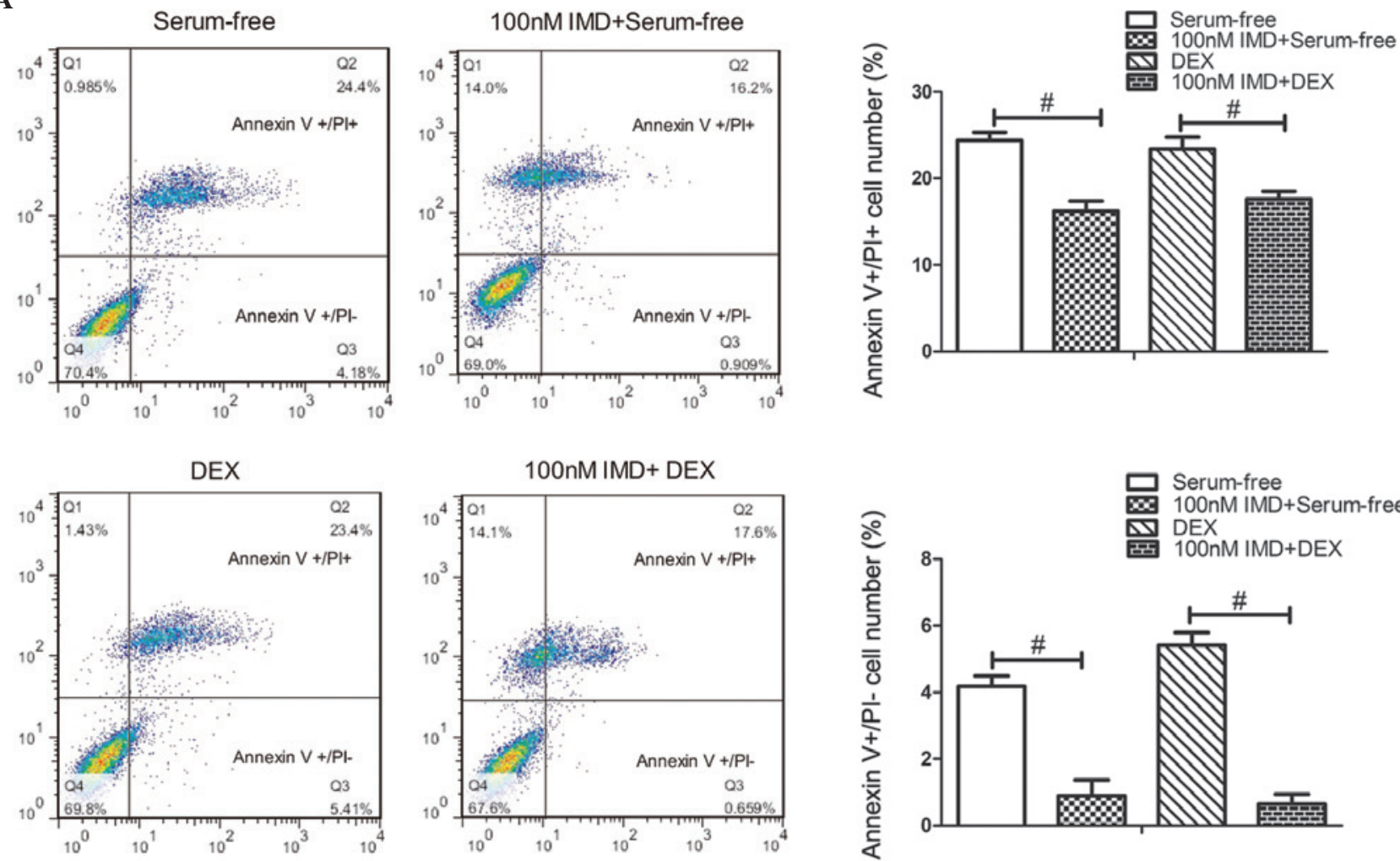

B

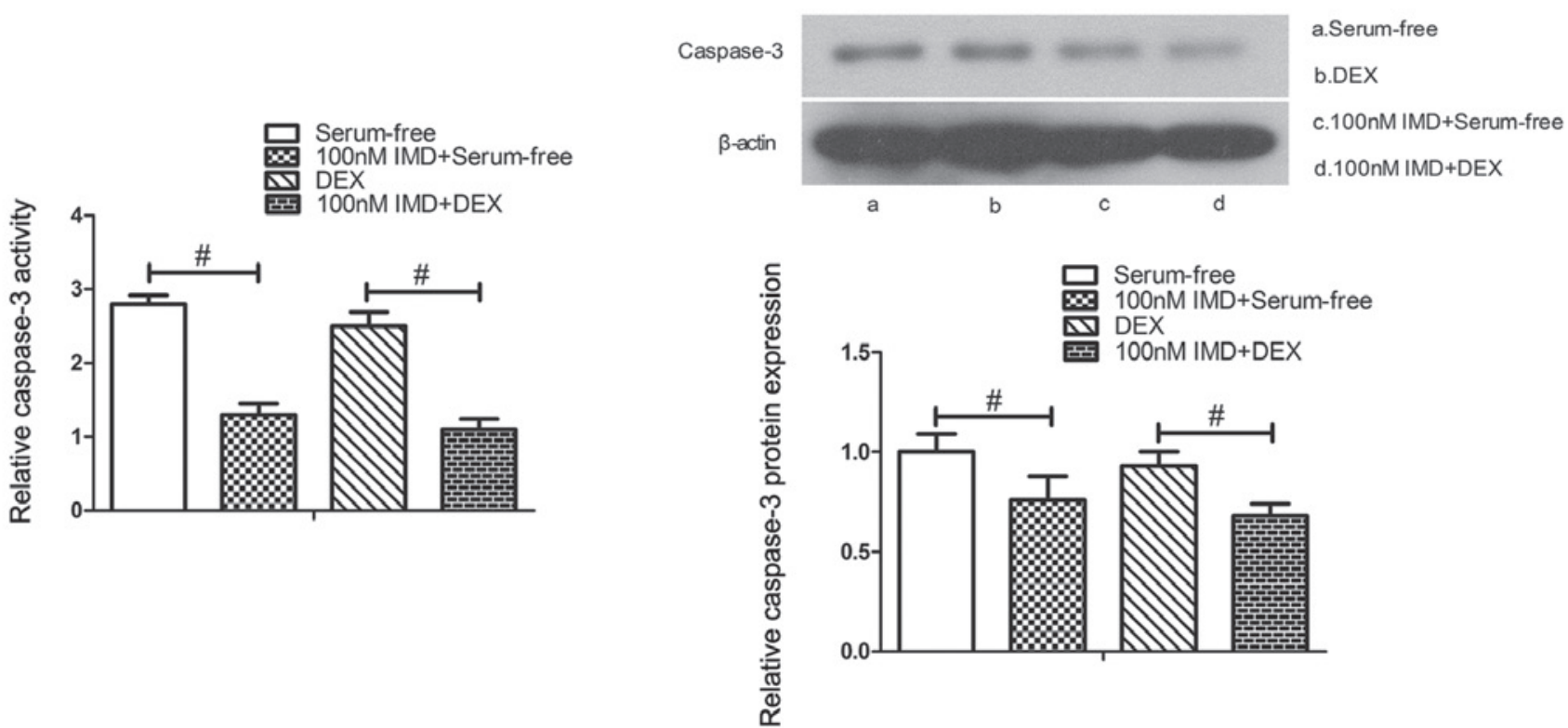

Figure 3. Effect of IMD on MC3T3-E1 cell apoptosis. (A) Flow cytometric analysis. Cell apoptosis was induced by incubation in serum-free medium or $10^{-7} \mathrm{M}$ DEX. Following treatment with IMD (1-100 nM), the number of PI-positive (Q2 quadrant) and annexin V-positive (Q3 quadrant) cells were measured. A significant decrease in apoptosis was observed in the $100 \mathrm{nM} \mathrm{IMD}$, compared with the serum-free or $10^{-7} \mathrm{M}$ DEX cultured cells. (B) Caspase-3 activity and protein expression were determined. Caspase- 3 activity and protein expression levels were significantly decreased in the $100 \mathrm{nM}$ IMD group, compared with the untreated culture group at $24 \mathrm{~h} .{ }^{~} \mathrm{P}<0.01$. Data are presented as the mean \pm standard deviation. IMD, intermedin; DEX, dexamethasone; PI, propidium iodide.

extracellular matrix and are able to mineralize into bone matrix $(22,23)$. ALP, OCN and BSP have been reported to be involved in the molecular events of osteoblast differentiation (24,25). Using MTT analysis, the present study demonstrated that IMD had no effect on the proliferation of the MC3T3-E1 osteoblast lineage. In addition, IMD treatment had no effect on ALP activity, Alizarin red staining or the mRNA expression levels of OCN and BSP, suggesting that IMD had no effect on the differentiation of osteoblasts. Notably, the results of the Annexin V/PI flow cytometry revealed that IMD significantly inhibited the apoptosis of the MC3T3-E1 cells. The present study subsequently measured caspase- 3 activity and protein expression levels and, in accordance with the above findings, IMD markedly attenuated caspase-3 activity and 

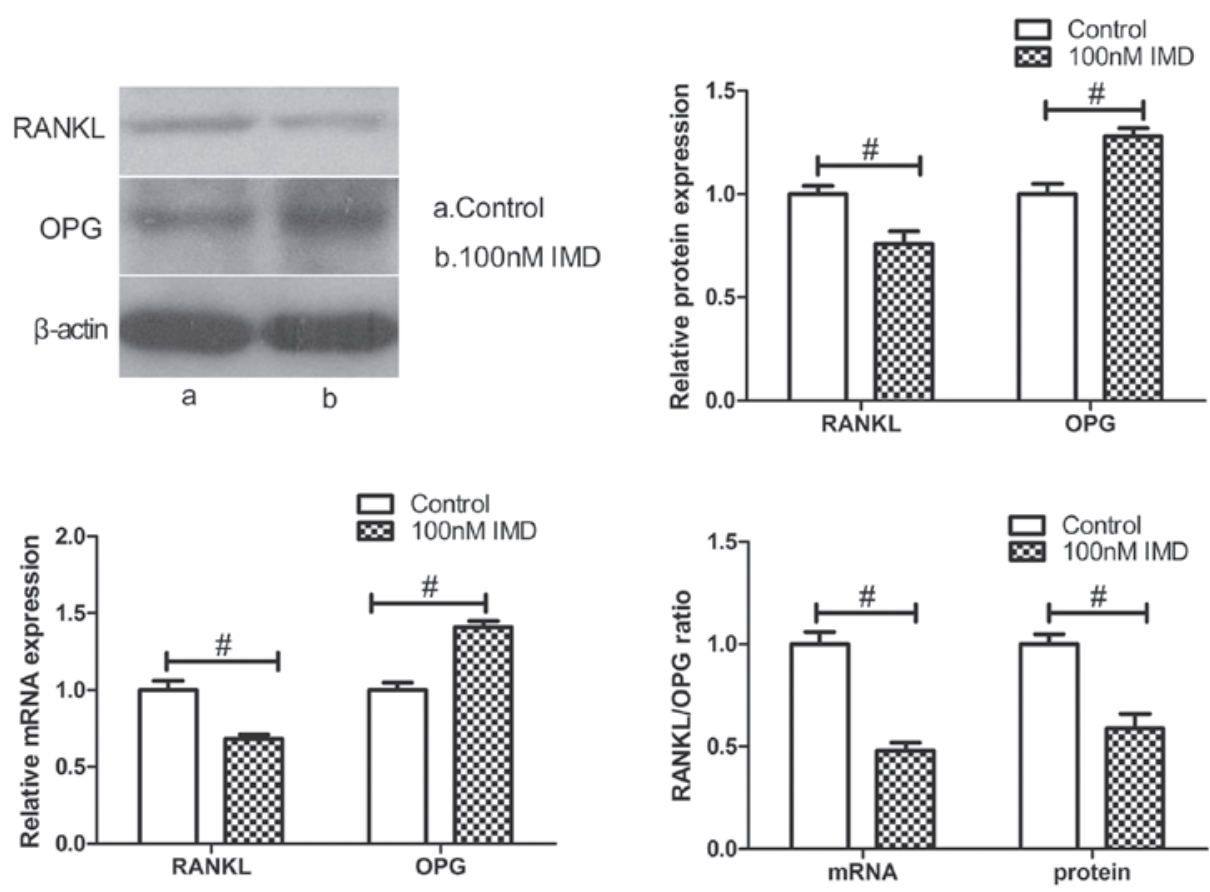

Figure 4. Effect of IMD on the expression ratio of RANKL/OPG. The MC3T3-E1 cells were treated with IMD (1-100 nM) for $48 \mathrm{~h}$. The results demonstrated that IMD significantly suppressed the expression of RANKL and enhanced the expression of OPG, compared with the control. Therefore, IMD downregulated the ratio of RANKL/OPG. " $\mathrm{P}<0.01$. Data are presented as the mean \pm standard deviation. IMD, intermedin; RANKL, receptor activator of NF- $\mathrm{kB}$ ligand; OPG, osteoprotegerin.
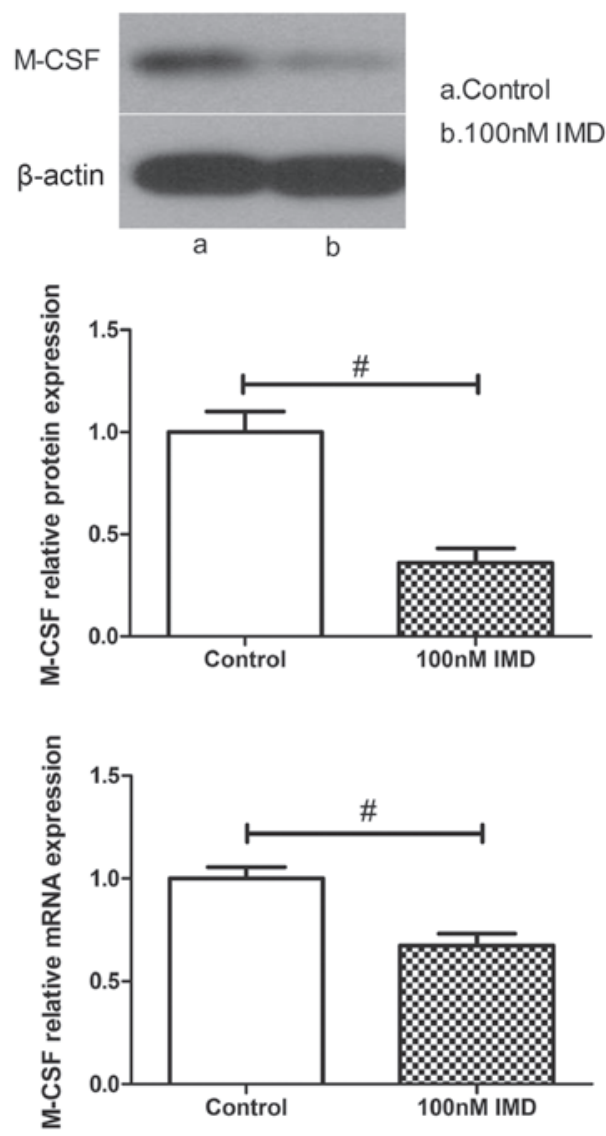

Figure 5. Effect of IMD on the expression of M-CSF. The mRNA and protein expression levels of M-CSF in the MC3T3-E1 cells were measured following treatment with (1-100 nM) IMD for $48 \mathrm{~h}$. Treatment with $100 \mathrm{nM}$ IMD significantly decreased the mRNA and protein expression levels of M-CSF. ${ }^{\text {" }} \mathrm{P}<0.01$. Data are presented as the mean \pm standard deviation. IMD, intermedin; M-CSF, macrophage colony-stimulating factor. decreased protein expression levels. These results indicated that IMD suppressed the apoptosis induced by serum-free medium or DEX in the MC3T3-E1 cells.

Osteoclasts originate from the monocyte/macrophage hematopoietic lineages and are responsible for bone resorption $(26,27)$. Previous studies have confirmed that osteoblasts can modulate osteoclast function by secreting RANKL, OPG and M-CSF (28-30). The OPG/RANKL/M-CSF system is fundamental for regulation between osteoblasts and osteoclasts (31). The expression of RANKL by osteoblast cells, is essential for osteoclast differentiation and maturity via its receptor, RANK, located on the osteoclast membrane (32) and M-CSF, which binds to its receptor, c-Fms, and appears to be necessary for osteoclast development $(33,34)$. OPG, produced by osteoblastic cells, inhibits osteoclast differentiation through its binding to RANKL (34). Thus, the RANKL/OPG ratio and the expression of M-CSF determine osteoclast activity in addition to bone resorption (35). The present study is the first, to the best of our knowledge, to provide insight into the effects of IMD on the imbalance of RANKL/OPG ratio and the expression of M-CSF. The data obtained in the present study demonstrated that IMD downregulated the ratio of RANKL/OPG and the expression of M-CSF at the mRNA and protein levels, suggesting that IMD is a novel negative regulator of OC function and resists bone resorption.

In conclusion, the results of the presents study demonstrated that IMD decreased apoptosis and also decreased the RANKL/OPG ratio and the expression of M-CSF in MC3T3-E1 cells. These results provide insight into the molecule mechanism underlying the inhibitory effects of IMD on bone resorption. 


\section{Acknowledgements}

This study was supported by the National Science Foundation of China (grant no. 81370981).

\section{References}

1. Roh J, Chang CL, Bhalla A, Klein C and Hsu SY: Intermedin is a calcitonin/calcitonin gene-related peptide family peptide acting through the calcitonin receptor-like receptor/receptor activity-modifying protein receptor complexes. J Biol Chem 279: 7264-7274, 2004.

2. Takei $\mathrm{Y}$, Inoue $\mathrm{K}$, Ogoshi $\mathrm{M}$, Kawahara T, Bannai $\mathrm{H}$ and Miyano S: Identification of novel adrenomedullin in mammals: A potent cardiovascular and renal regulator. FEBS Lett 556: 53-58, 2004.

3. Chauhan M, Balakrishnan M, Yallampalli U, Endsley J, Hankins GD, Theiler R and Yallampalli C: Adrenomedullin $2 /$ intermedin regulates HLA-G in human trophoblasts. Biol Reprod 85: 1232-1239, 2011.

4. Takahashi K, Kikuchi K, Maruyama Y, Urabe T, Nakajima K, SasanoH,ImaiY,MurakamiOandTotsuneK:Immunocytochemical localization of adrenomedullin 2/intermedin-like immunoreactivity in human hypothalamus, heart and kidney. Peptides 27 1383-1389, 2006.

5. Takahashi K, Morimoto R, Hirose $T$, Satoh $F$ and Totsune K: Adrenomedullin 2/intermedin in the hypothalamo-pituitary-adrenal axis. J Mol Neurosci 43: 182-192, 2011.

6. Chauhan M, Yallampalli U, Dong YL, Hankins GD and Yallampalli C: Expression of adrenomedullin 2 (ADM2)/intermedin (IMD) in human placenta: Role in trophoblast invasion and migration. Biol Reprod 81: 777-783, 2009.

7. McLatchie LM, Fraser NJ, Main MJ, Wise A, Brown J, Thompson N, Solari R, Lee MG and Foord SM: RAMPs regulate the transport and ligand specificity of the calcitonin-receptor-like receptor. Nature 393: 333-339, 1998

8. Pan CS, Yang JH, Cai DY, Zhao J, Gerns H, Yang J, Chang JK, Tang CS and Qi YF: Cardiovascular effects of newly discovered peptide intermedin/adrenomedullin 2. Peptides 26: 1640-1646, 2005.

9. Fujisawa Y, Nagai Y, Miyatake A, Takei Y, Miura K, Shoukouji T, Nishiyama A, Kimura S and Abe Y: Renal effects of a new member of adrenomedullin family, adrenomedullin2, in rats. Eur J Pharmacol 497: 75-80, 2004.

10. Holmes D, Campbell M, Harbinson M and Bell D: Protective effects of intermedin on cardiovascular, pulmonary and renal diseases: Comparison with adrenomedullin and CGRP. Curr Protein Pept Sci 14: 294-329, 2013.

11. Granholm S, Lundberg P and Lerner UH: Expression of the calcitonin receptor, calcitonin receptor-like receptor, and receptor activity modifying proteins during osteoclast differentiation. J Cell Biochem 104: 920-933, 2008.

12. Naot D and Cornish J: The role of peptides and receptors of the calcitonin family in the regulation of bone metabolism. Bone 43: 813-818, 2008

13. Granholm S, Henning $\mathrm{P}$ and Lerner UH: Comparisons between the effects of calcitonin receptor-stimulating peptide and intermedin and other peptides in the calcitonin family on bone resorption and osteoclastogenesis. J Cell Biochem 112 3300-3312, 2011

14. Uzan B, de Vernejoul MC and Cressent M: RAMPs and CRLR expressions in osteoblastic cells after dexamethasone treatment. Biochem Biophys Res Commun 321: 802-808, 2004.
15. Livak KJ and Schmittgen TD: Analysis of relative gene expression data using real-time quantitative PCR and the 2(-Delta Delta C(T)) Method. Methods 25: 402-408, 2001

16. Hsu WL, Chen CY, Tsauo JY and Yang RS: Balance control in elderly people with osteoporosis. J Formos Med Assoc 113: 334-339, 2014.

17. Manolagas SC and Jilka RL: Bone marrow, cytokines and bone remodeling. Emerging insights into the pathophysiology of osteoporosis. N Engl J Med 332: 305-311, 1995.

18. Brunner M, Jurdic P, Tuckerman JP, Block MR and Bouvard D: New insights into adhesion signaling in bone formation. Int Rev Cell Mol Biol 305: 1-68, 2013.

19. Roodman GD: Advances in bone biology: The osteoclast. Endocr Rev 17: 308-332, 1996.

20. Roux S and Orcel P: Bone loss. Factors that regulate osteoclast differentiation: An update. Arthritis Res 2: 451-456, 2000.

21. Reid IR: Anti-resorptive therapies for osteoporosis. Semin Cell Dev Biol 19: 473-478, 2008.

22. Long F: Building strong bones: Molecular regulation of the osteoblast lineage. Nat Rev Mol Cell Biol 13: 27-38, 2011.

23. Matsumura S, Hiranuma H, Deguchi A, Maeda T, Jikko A and Fuchihata H: Changes in phenotypic expression of osteoblasts after X irradiation. Radiat Res 149: 463-471, 1998.

24. Matsuguchi T, Chiba N, Bandow K, Kakimoto K, Masuda A and Ohnishi T: JNK activity is essential for Atf4 expression and late-stage osteoblast differentiation. J Bone Miner Res 24: 398-410, 2009.

25. Kim HK, Cho SG, Kim JH, Doan TK, Hu QS, Ulhaq R, Song EK and Yoon TR: Mevinolin enhances osteogenic genes (ALP, type I collagen and osteocalcin), CD44, CD47 and CD51 expression during osteogenic differentiation. Life Sci 84: 290-295, 2009.

26. Boyle WJ, Simonet WS and Lacey DL: Osteoclast differentiation and activation. Nature 423: 337-342, 2003.

27. Zhao Q, Shao J, Chen W and Li YP: Osteoclast differentiation and gene regulation. Front Biosci 12: 2519-2529, 2007.

28. Simonet WS, Lacey DL, Dunstan CR, Kelley M, Chang MS, Lüthy R, Nguyen HQ, Wooden S, Bennett L, Boone T, et al: Osteoprotegerin: A novel secreted protein involved in the regulation of bone density. Cell 89: 309-319, 1997.

29. Martin T, Gooi JH and Sims NA: Molecular mechanisms in coupling of bone formation to resorption. Crit Rev Eukaryot Gene Expr 19: 73-88, 2009

30. Khosla S: Minireview: The OPG/RANKL/RANK system. Endocrinology 142: 5050-5055, 2001.

31. Kaji H, Kanatani M, Sugimoto T and Chihara K: Statins modulate the levels of osteoprotegerin/receptor activator of NFkappaB ligand mRNA in mouse bone-cell cultures. Horm Metab Res 37: 589-592, 2005.

32. Giuliani N, Colla S, Sala R, Moroni M, Lazzaretti M, La Monica S, Bonomini S, Hojden M, Sammarelli G, Barillè S, et al: Human myeloma cells stimulate the receptor activator of nuclear factor-kappa B ligand (RANKL) in T lymphocytes: A potential role in multiple myeloma bone disease. Blood 100: 4615-4621, 2002.

33. Udagawa N, Takahashi N, Akatsu T, Tanaka H, Sasaki T, Nishihara T, Koga T, Martin TJ and Suda T: Origin of osteoclasts: Mature monocytes and macrophages are capable of differentiating into osteoclasts under a suitable microenvironment prepared by bone marrow-derived stromal cells. Proc Natl Acad Sci USA 87: 7260-7264, 1990.

34. Jimi E, Akiyama S, Tsurukai T, Okahashi N, Kobayashi K, Udagawa N, Nishihara T, Takahashi N and Suda T: Osteoclast differentiation factor acts as a multifunctional regulator in murine osteoclast differentiation and function. J Immunol 163: 434-442, 1999.

35. Abdallah BM, Stilgren LS, Nissen N, Kassem M, Jorgensen HR and Abrahamsen B: Increased RANKL/OPG mRNA ratio in iliac bone biopsies from women with hip fractures. Calcif Tissue Int 76: 90-97, 2005. 